\title{
Emi1 regulates the anaphase-promoting complex by a different mechanism than Mad2 proteins
}

\author{
Julie D.R. Reimann, Bryan E. Gardner, Florence Margottin-Goguet, and Peter K. Jackson ${ }^{1}$ \\ Departments of Pathology, Microbiology and Immunology, Stanford University School of Medicine, \\ Stanford, California 94305-5324, USA
}

\begin{abstract}
The anaphase-promoting complex/cyclosome (APC) ubiquitin ligase is activated by Cdc20 and Cdh1 and inhibited by Mad2 and the spindle assembly checkpoint complex, Mad2B, and the early mitotic inhibitor Emi1. Mad2 inhibits APC ${ }^{\text {Cde20 }}$, whereas Mad2B preferentially inhibits APC ${ }^{\text {Cdh1 }}$. We have examined the mechanism of APC inhibition by Emi1 and find that unlike Mad2 proteins, Emi1 binds and inhibits both $\mathrm{APC}^{\mathrm{Cdh} 1}$ and $\mathrm{APC}^{\mathrm{Cde20}}$. Also unlike Mad2, Emi1 stabilizes cyclin A in the embryo and requires zinc for its APC inhibitory activity. We find that Emil binds the substrate-binding region of Cdc20 and prevents substrate binding to the APC, illustrating a novel mechanism of APC inhibition.
\end{abstract}

[Key Words: Emi1; Cdc20; Cdh1; APC; Mad2; mitosis]

Received September 18, 2001; revised version accepted October 29, 2001.

The anaphase-promoting complex/cyclosome (APC) is a ubiquitin ligase that controls mitotic progression by ubiquitylating key mitotic regulators, including the anaphase inhibitor securin and the mitotic cyclins A and B, targeting them for destruction by the $26 \mathrm{~S}$ proteasome (for review, see Page and Hieter 1999; Zachariae and Nasmyth 1999). The APC is present throughout the cell cycle, but selective binding of the activator proteins $\mathrm{Cdc} 20$ or $\mathrm{Cdh} 1$ results in a peak of $\mathrm{APC}^{\mathrm{Cdc} 20}$ activity in mitosis and $A P C{ }^{C d h} 1$ activity in late mitosis and $\mathrm{G}_{1}$ (Sigrist and Lehner 1997; Visintin et al. 1997; Fang et al. 1998b; Kramer et al. 1998, 2000; Lorca et al. 1998; Prinz et al. 1998; Zachariae et al. 1998).

Cdc20 and Cdh1 target for ubiquitylation proteins containing a destruction box motif (D-box; Glotzer et al. 1991). Cdh1 also recognizes proteins with a KEN-box motif (Pfleger and Kirschner 2000). APC substrates were recently found to bind and be recruited directly to the APC by Cdc20/Cdh1 in a D-box- and KEN-box-dependent manner (Burton and Solomon 2001; Hilioti et al. 2001; Pfleger et al. 2001a).

APC substrate destruction is temporally regulated: cyclin A in prometaphase, securin at metaphase-anaphase, and the mitotic polo-like kinase upon mitotic exit /Cohen-Fix et al. 1996; Shirayama et al. 1998; den Elzen and Pines 2001; Geley et al. 2001). Tight regulation of APC activity ensures the sequential destruction of APC sub-

${ }^{1}$ Corresponding author.

E-MAIL pjackson@cmgm.stanford.edu; FAX (650) 725-6902.

Article and publication are at http://www.genesdev.org/cgi/doi/10.1101/ gad. 945701 . strates and the correct timing of mitotic events. We recently identified the APC inhibitor Emil, which binds Cdc20 to inhibit premature APC activation in mitosis (Reimann et al. 2001). In Xenopus embryos, Emil is required for cyclin B accumulation and mitotic entry and Emil destruction is required for mitotic exit.

$\mathrm{APC}^{\mathrm{Cdc} 20}$ activity is also regulated by the spindle assembly checkpoint (SC), a pathway that delays sister chromatid separation until chromosome alignment at metaphase (for review, see Shah and Cleveland 2000). The SC protein Mad2 acts at unattached kinetochores in prometaphase to inhibit the APC until chromosome alignment, and is activated following spindle damage. Mad2 binds and inhibits Cdc20 in vitro (Fang et al. 1998a; Hwang et al. 1998; Kallio et al. 1998; Kim et al. 1998). BubR1, another SC component, also forms a complex with Cdc20 and inhibits APC activation by Cdc20 in vitro (Sudakin et al. 2001; Tang et al. 2001). The Mad2-like protein Mad2B was recently identified as an $\mathrm{APC}^{\mathrm{Cdh} 1}$ inhibitor in vitro and in vivo /Chen and Fang 2001; Pfleger et al. 2001b). Mad2 and Mad2B have been proposed to inhibit APC activity by inhibiting substrate release from $\mathrm{APC}^{\mathrm{Cdc} 20}$ and $\mathrm{APC}^{\mathrm{Cdh} 1}$, respectively (Pfleger et al. 2001b).

To understand how Emil regulates APC activity, we investigated its APC inhibitory activity in several different assays. We find that Emil inhibits Cdh1-APC as well as Cdc20-APC activation, acting more broadly than either Mad2 or Mad2B. Unlike Mad2 or Mad2B, Emi1 can inhibit APC already activated by Cdc20 or Cdh1. Emil binds the Cdc20 N terminus in the substrate-binding region, and directly inhibits substrate binding to 
Cdc20, potentially explaining its mechanism of APC inhibition.

\section{Results}

\section{Emi1 binds Cdh1 and inhibits $A P C^{C d h 1}$ activity}

Studies of the likely Drosophila homolog of Emi1, Regulator of cyclin A (Rcal), show that Rcal overexpression in $\mathrm{G}_{1}$ cells stabilizes cyclin A (Dong et al. 1997). Cdh1 activates the APC to ubiquitylate cyclin A and other $G_{1}$ substrates (for review, see Zachariae and Nasmyth 1999). Because Emil binds and inhibits Cdc20, we considered whether Emil also inhibits the related protein Cdh1. Baculovirus-expressed Emil and Cdh1 coimmunoprecipitated from insect cell lysate and ${ }^{35}$ S-labeled Cdh1 precipitated with GST-Emil protein (Fig. 1A). Human Emil and Cdh1 also form a complex in vivo (J. Hsu, J. Reimann, C. Sorensen, J. Lukas, and P. Jackson, in prep.).

Next, we tested whether Emil inhibits APC ${ }^{C d h 1}$ activity in Xenopus egg extracts. Radiolabeled in vitro translated (IVT) cyclin B and securin are stable in interphase extracts, where the APC is inactive (Fig. 1B). Ad- dition of IVT Cdh1 to these extracts activated the APC for cyclin B and securin destruction. Emil addition to these Cdh1-supplemented extracts stabilized cyclin B and securin (Fig. 1B). Emil also inhibited Cdh1 activation of APC immunopurified from interphase extracts in a dose-dependent manner (Fig. 1C). Mad2, which does not interact with Cdh1, did not (Fig. 1C), as described (Chen and Fang 2001; Pfleger et al. 2001b). As with Cdc20 (Reimann et al. 2001), the Emil C but not the $\mathrm{N}$ terminus is sufficient to block $\mathrm{APC}^{\mathrm{Cdh} 1}$ activation (data not shown). Human Emil also inhibits both Cdc20 and Cdh1-APC activation in vitro and in vivo, indicating a conserved APC regulatory role for Emil (J. Hsu, J. Reimann, C. Sorensen, J. Lukas, and P. Jackson, in prep.). Neither Emil nor Mad2 inhibited the ubiquitylation activity of the core APC enzymatic components APC2/ APC11 (Fig. 1D; Gmachl et al. 2000), further suggesting that both inhibitors act through Cdc20 or Cdh1.

Emil alignment with homologs from other organisms (Reimann et al. 2001) highlighted a conserved N-terminal KEN sequence, typically found in $\mathrm{APC}^{\mathrm{Cdh} 1}$ substrates (Pfleger and Kirschner 2000). Emil is degraded in mitosis independent of the APC in the embryo (Reimann
A

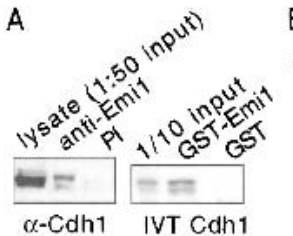

C
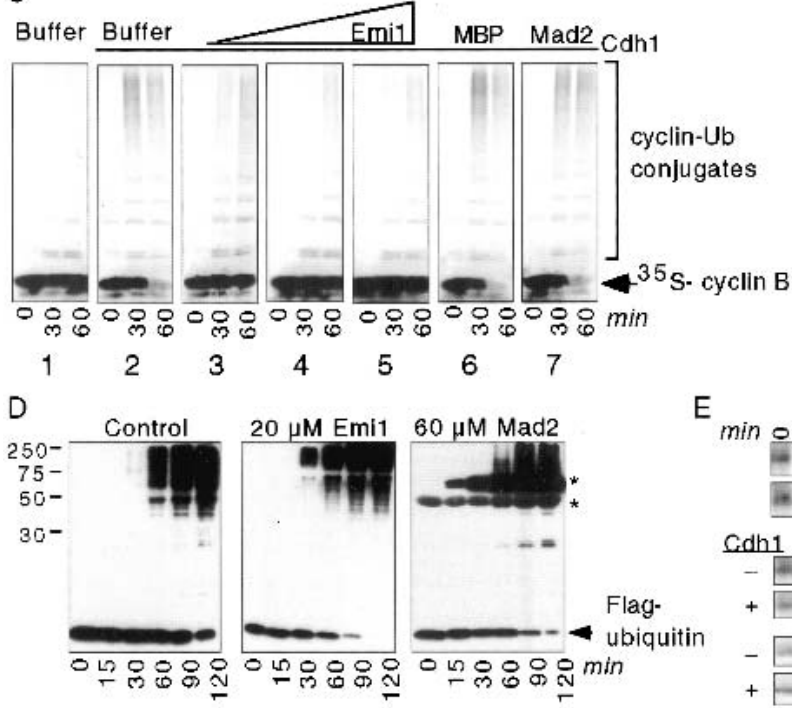

E
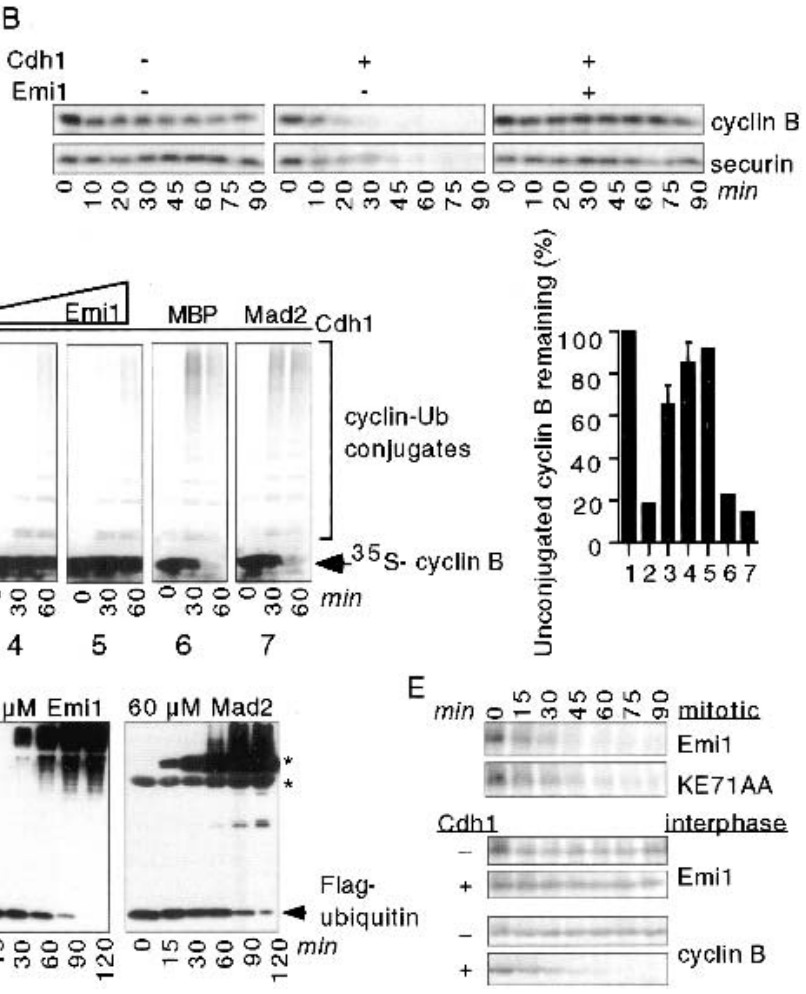

Figure 1. Emil binds Cdh1 and inhibits APC $^{\text {Cdh1 }}$ activity. (A) Emil interacts with Cdh1. SF9 cells were coinfected with baculoviruses expressing Emil and Cdh1, lysed, and lysates precipitated with preimmune (PI) or anti-Emil antisera and analyzed for Cdh1 by immunoblotting (left). GST-Emil or GST was incubated with ${ }^{35} \mathrm{~S}$-labeled in vitro translated (IVT) Cdh1, bound to glutathione agarose, and analyzed by SDS-PAGE and autoradiography (right). (We typically observe $\sim 20$ $30 \%$ of input ${ }^{35} \mathrm{~S}$-labeled Cdh1 precipitating with GST-Emi1.) (B) Emil inhibits APC Cdh1 activity in Xenopus egg extracts. ${ }^{35}$ S-labeled IVT $\mathrm{N}$ terminus $X$ cyclin B or Xsecurin was incubated in Xenopus interphase extracts treated with buffer, buffer + IVT Cdh1, or IVT Cdh1 plus MBP-Emil (1 $\mu \mathrm{M})$. Aliquots were removed at the indicated times and analyzed by SDS-PAGE and autoradiography. $(C)$ Emil, but not Mad2, inhibits APC ${ }^{\mathrm{Cdh} 1}$-dependent activation in vitro. IVT Cdh1 (panels 2-7) or rabbit reticulocyte lysate (1) was incubated with buffer (1 and 2), MBP-Emil $(3,1 \mu \mathrm{M} ; 4$, $3 \mu \mathrm{M} ; 5,10 \mu \mathrm{M}), 10 \mu \mathrm{M}$ MBP (6), or $80 \mu \mathrm{M}$ GST-Mad2 (7). APC immunopurified from interphase egg extracts was then incubated with the Cdh1/protein mixtures. The ability of treated APC to ubiquitylate ${ }^{35} \mathrm{~S}$-labeled N-terminal cyclin B fragment was assayed. The percentage of cyclin B remaining unconjugated to ubiquitin after 60 min was quantitated on a PhosphorImager (graph). (D) Neither Emil nor Mad2 inhibits the substrate-independent reaction of the APC. Baculovirusexpressed and purified APC2/APC11 was incubated with $20 \mu \mathrm{M}$ MBP (control), $20 \mu \mathrm{M}$ MBP-Emil, or $60 \mu \mathrm{M}$ GST-Mad2 in the presence of E1, E2, ATP, and Flag-tagged ubiquitin. Aliquots were taken at the indicated times and analyzed for the formation of polyubiquitin chains by immunoblotting with $\alpha$ Flag antibodies. $\left({ }^{*}\right.$, GST-Mad2; $\alpha$ Flag antibody cross-reacts with GST, which is ubiquitylated in this assay.) (E) Emil destruction is not mediated by APC ${ }^{\mathrm{Cdh} 1}$. ${ }^{35}$ S-labeled IVT wild-type Emi1, KE71AA mutant (substitution of K 71 and E 72 with alanines), or N terminus cyclin B fragment was added to mitotic extracts, interphase extracts, or Cdh1-supplemented interphase extracts. Aliquots were removed at the indicated times and analyzed for substrate destruction by SDS-PAGE and autoradiography. 
et al. 2001), but Cdh1 is not present in Xenopus embryos (Lorca et al. 1998). To test whether Emil is an APC Cdh1 substrate, we assayed the stability of ${ }^{35}$ S-labeled Emil in Cdh1-supplemented interphase extracts. Cdh1 addition to extracts destabilized cyclin B but not Emil (Fig. 1E). Additionally, a KEN box mutant (KE71AA) did not stabilize Emil in mitotic extracts (Fig. 1E), and Emil was not ubiquitylated by $\mathrm{APC}^{\mathrm{Cdh} 1}$ in vitro (data not shown). Thus, Emil does not appear to be an $\mathrm{APC}^{\mathrm{Cdc} 20}$ or $\mathrm{APC}^{\mathrm{Cdh} 1}$ substrate, but rather a Cdh1/Cdc20 regulator.

\section{Emi1 but not Mad2 stabilizes cyclin A in Xenopus eggs}

APC-dependent cyclin A destruction in prometaphase is not inhibited by the SC (Hunt et al. 1992; den Elzen and Pines 2001; Geley et al. 2001). In contrast, Emil prevents cyclin A destruction in Xenopus eggs (Fig. 2A; Reimann et al. 2001), whereas addition of GST-Mad2 to cycling extracts prevented cyclin B but not cyclin A destruction (Fig. 2B). Thus, unlike Emi1, Mad2 is not competent to stabilize cyclin A in either somatic or embryonic cells.

Cyclin A is a key APC ${ }^{\text {Cdh1 }}$ target in $G_{1}$ (Lukas et al. 1999; Sørensen et al. 2001), so we tested Emil inhibition of $\mathrm{APC}^{\mathrm{Cdh} 1}$-mediated cyclin A ubiquitylation. Emil blocked APC ${ }^{\mathrm{Cdh} 1}$ ubiquitylation of cyclin A in a dosedependent manner (Fig. 2D). Human Emil also inhibits APC $^{\text {Cdh1 } 1}$-mediated cyclin A ubiquitylation in vitro and in vivo (J. Hsu, J. Reimann, C. Sorensen, J. Lukas, and P. Jackson, in prep.), indicating conservation of Emil's ability to regulate cyclin A stability.

\section{Emi1 interacts with and inhibits Cdc20/Cdh1 already bound to the APC}

Fractionation experiments show separate Emil-Cdc20 and $\mathrm{APC}^{\mathrm{Cdc} 20}$ complexes in eggs (Reimann et al. 2001). However, exogenously added Emil can inhibit the APC in mitotic egg extracts, where the APC is already acti- vated by Cdc20. One possibility is that Cdc20-APC binding is dynamic, and exogenous Emil sequesters Cdc20 as it dissociates from the APC. An alternative explanation is that exogenous Emil binds and inhibits Cdc20 already associated with the APC. Emil may fail to bind $\mathrm{APC}^{\mathrm{Cdc} 20}$ in mitotic extracts because Emil is already degraded before Cdc20 is fully bound to the APC (Reimann et al. 2001). We found that ${ }^{35}$ S-labeled Emil precipitated with APC prebound to either IVT Cdc20 or Cdh1, but not to APC preincubated with reticulocyte lysate or with control beads; Emil reproducibly bound APC $^{\text {Cdh } 1}$ more strongly than it did APC ${ }^{\mathrm{Cd} 20}$ (Fig. 3A). Emil did not prevent Cdc20 or Cdh1 binding to the APC in vitro; when IVT ${ }^{35}$ S-labeled Cdc20 or Cdh1 was incubated with APC beads, a similar amount of either protein was recovered in the presence or absence of Emil (Fig. 3B; data not shown).

We next tested whether Emil could inhibit immunopurified APC already activated by Cdc20/Cdh1. Emi1 addition to preformed $\mathrm{APC}^{\mathrm{Cdh} 1}$ complexes inhibited cyclin B ubiquitylation to a similar extent as when Cdh1 was preincubated with Emil (Fig. 3C). Preincubation of the APC with Emil reduced activation by Cdh1 somewhat, consistent with the small amount of Emil that associates with the APC in our binding assays (Fig. 2A). We

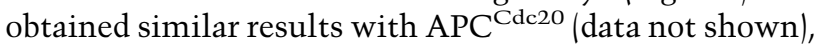
indicating that Emil can inhibit the APC with either Cdc20 or Cdh1 already bound.

\section{Emi1 inhibits substrate binding to Cdc20}

The N-terminal 158 residues of Cdc20 are sufficient for binding to Emil (Reimann et al. 2001). This Cdc20 fragment contains both a Mad2-binding region (MBR, residues 118-158) and a substrate-binding region (SBR, residues 1- 118) (Luo et al. 2000; Pfleger et al. 2001a; Zhang and Lees 2001). We tested Emil binding to these domains, and found that Emil specifically bound the Cdc20 SBR, and not the MBR (Fig. 3E). Both Cdc20 bind-
Figure 2. Emil but not Mad2 inhibits cyclin A destruction in Xenopus eggs. $(A, B)$ Emil prevents cyclin A and B destruction in egg extracts whereas Mad2 only stabilizes cyclin B. Activated Xenopus cycling egg extracts were incubated with buffer alone, MBP-Emi1, or GST-Mad2. Aliquots were removed at the indicated times and assayed for Xenopus cyclins A and B by immunoblotting. $(C)$ Emil inhibits $\mathrm{APC}^{\mathrm{Cdh} 1}$-mediated cyclin A ubiquitylation in vitro. IVT Cdh1 (panels 2-5) or rabbit reticulocyte lysate (1) was incubated with buffer (1 and 2), MBP-Emil (3, 3 $\mu \mathrm{M} ; 4,6 \mu \mathrm{M}$ ), or $6 \mu \mathrm{M}$ MBP (5). APC immunopurified from interphase egg extracts was incubated with the Cdh1/protein mixtures. The ability of treated APC to ubiquitylate ${ }^{35}$ S-labeled cyclin A was assayed. The percentage of cyclin A remaining unconjugated to ubiquitin after 60 min was quantitated on a PhosphorImager (graph).

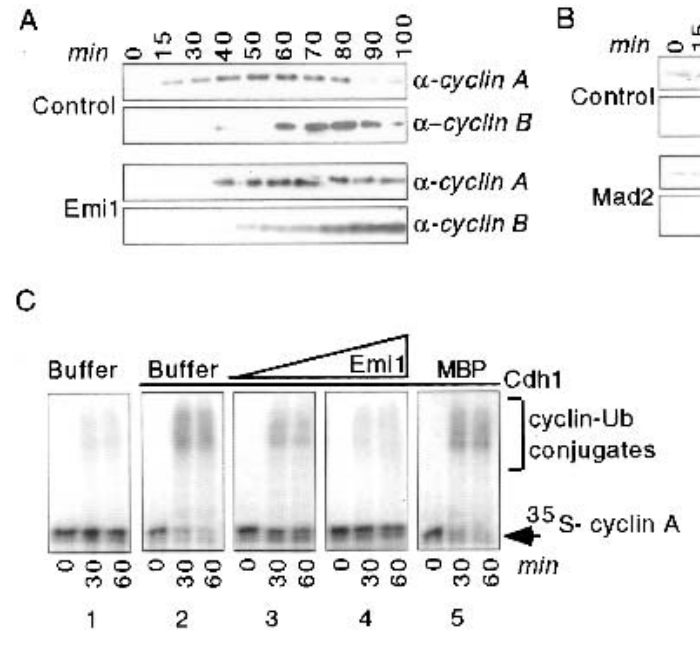




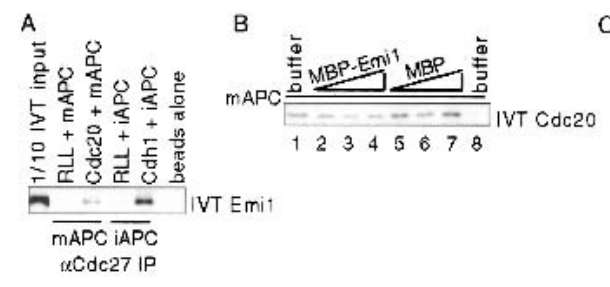

$\mathrm{E}$

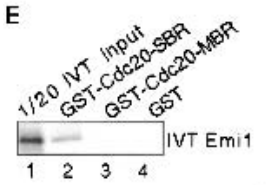

F
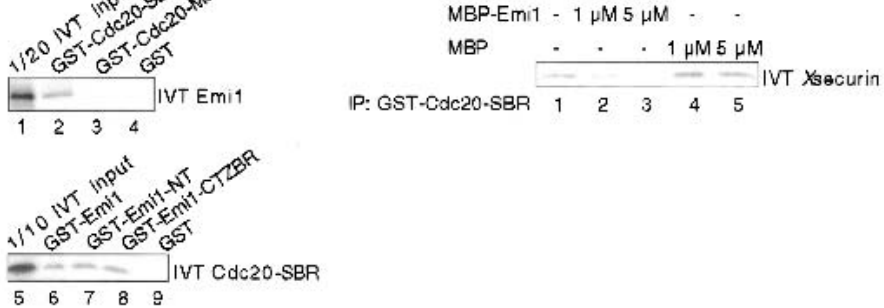
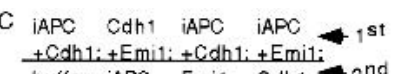
buffer iAPC Emi1 Cdh1 $2^{\text {nd }}$
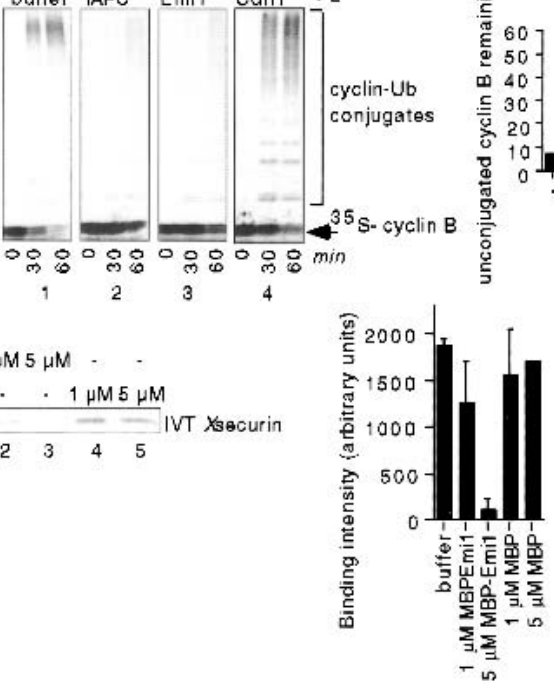

D
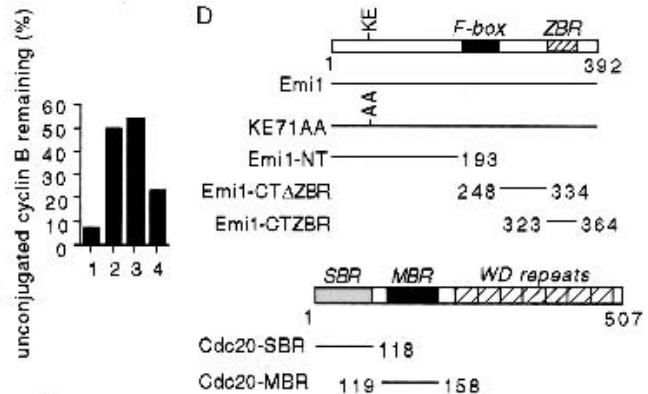

Figure 3. Emil inhibits substrate binding to the APC. (A) Emil can bind Cdc20 and Cdh1 already associated with the APC. Mitotic $(\mathrm{m})$, interphase (i), or no APC was immobilized on $\alpha \mathrm{Cdc} 27$ beads, bound to rabbit reticulocyte lysate, IVT Cdc20, or IVT Cdh1, and then incubated with ${ }^{35}$ S-labeled IVT Emil. Bound Emil was analyzed by SDS/PAGE and autoradiography. $(B)$ Emil does not prevent Cdc20 binding to the APC in vitro. ${ }^{35}$ S-labeled IVT Cdc20 was preincubated with buffer (lanes 1 and 8$)$, MBP-Emi1 $(2,1 \mu M ; 3,3 \mu M$; $4,6 \mu \mathrm{M})$ or $\mathrm{MBP}(5,1 \mu \mathrm{M} ; 6,3 \mu \mathrm{M} ; 7,6 \mu \mathrm{M})$ and then incubated with mitotic APC (1-7) or no APC (8) on $\alpha$ Cdc27 beads. Bound Cdc20 was analyzed as in $A$. (C) Emil inhibits previously activated APC. Interphase APC (iAPC) complex immobilized on $\alpha$ Cdc27 beads was first incubated with IVT Cdh1 (panels 1 and 3), buffer (2), or $10 \mu \mathrm{M}$ MBP-Emi1 (4). Beads were then washed and incubated with buffer (1), IVT Cdh1 + $10 \mu \mathrm{M}$ MBP-Emil (2), $10 \mu \mathrm{M}$ MBP-Emil (3), or IVT Cdh1 (4). APC beads were washed and then assayed for cyclin B ubiquitylation activity. The percentage of cyclin B remaining unconjugated to ubiquitin after 60 min was quantitated on a PhosphorImager (graph). (D) Schematics of Emil and Cdc20 constructs used in this study. Emil F-box (residues 196-245), Emil zinc-binding region (ZBR, residues 323-364), Cdc20 substrate-binding region (SBR, residues 1-118), Cdc20 Mad2-binding region (MBR, residues 119-158), and Cdc20 WD-repeats (residues 181-480) are indicated. (E) Emil binds the substrate-binding region (SBR) of Cdc20. GST fusion proteins (lane 2, GST-Cdc20-SBR; 3, GST-Cdc20-MBR; 4 and 9, GST; 6, GST-Emil; 7, GST-Emi1-NT; 8, GST-Emi1-CTZBR) were incubated with ${ }^{35}$ S-labeled IVT Emil or Cdc20-SBR, bound to glutathione agarose, and analyzed as in $A$. $(F)$ Emil can inhibit substrate binding to Cdc20. GST-Cdc20-SBR $(1 \mu \mathrm{M})$ was prebound to glutathione agarose and then incubated with buffer (lane 1), MBP-Emi1 (lanes 2,3) or MBP (lanes 4,5). ${ }^{35}$ S-labeled IVT Xsecurin was then added and the amount of securin bound to Cdc20 was analyzed as in $A$ and was quantitated on a PhosphorImager (graph).

ing domains of Emil (the Emil $\mathrm{N}$ terminus and zincbinding region; Reimann et al. 2001) interact specifically with the Cdc20 SBR (Fig. 3E).

Because both Emil and substrates bind the Cdc20 SBR, we assayed the ability of Emil to inhibit substrate binding to Cdc20. MBP-Emil addition strongly reduced ${ }^{35} \mathrm{~S}$ labeled securin from binding to the Cdc20 SBR in a dosedependent manner (Fig. 3F). Using this substrate-binding assay, we find that Emil proteolytically cleaved and purified from MBP and a purified his-tagged Emil (which both inhibit APC activity similarly) also inhibit substrate-Cde20 binding (data not shown). GST-Mad2 did not inhibit substrate binding to Cdc20 in our assay, consistent with earlier results (Pfleger et al. 2001b). Emil also blocks substrate binding to Cdh1 in vitro (data not shown), providing further evidence of the role of Emil as a general substrate inhibitor of APC activity.

\section{Zinc is required for Emi1 to inhibit APC activity}

A highly conserved cluster of cysteines and histidine in Emil, a likely zinc-binding region (ZBR), is required for inhibiting APC activity (Reimann et al. 2001). Here, we found that at high concentrations, the Emil ZBR fragment is sufficient to inhibit APC activity in vitro (Fig. 4A).

To formally test whether zinc is required for Emil's inhibitory activity, we chelated zinc from the Emil protein with the zinc chelator TPEN. The ability of TPENtreated MBP-Emil to inhibit APC activity was strongly reduced and was restored by zinc addition (Fig. 4B). We see similar loss of activity with DPTA, another zinc chelator, and with zinc chelation from the Emil C terminus fragment.

\section{Discussion}

The APC is regulated by multiple mechanisms, including phosphorylation and binding of the Cdc20/Cdh1 activators or the Mad2 and Emil inhibitor proteins. Cdc20-APC activation is regulated by Emil, Mad2, and the SC proteins including BubR1; Cdh1 activation of the APC is regulated by Mad2B and as shown here by Emil. The activity of Emil toward the APC is partially con- 


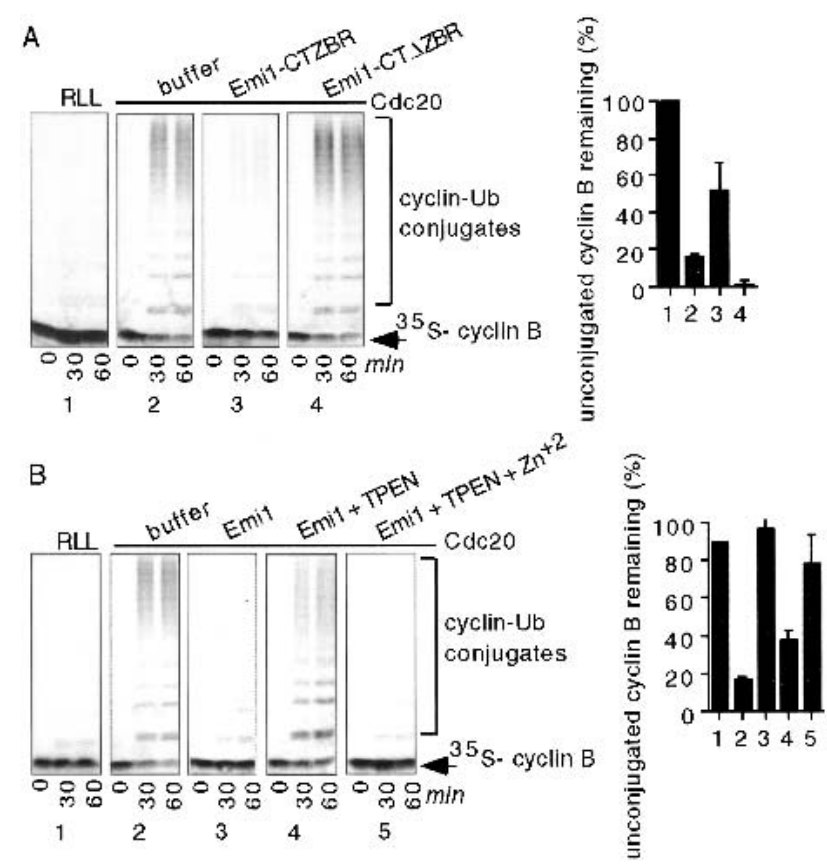

Figure 4. Zinc is required for the APC inhibitory activity of Emil in vitro. (A) The zinc-binding region (ZBR) of Emil is sufficient to inhibit the APC in vitro. IVT Cdc20 (panels 2-4) or rabbit reticulocyte lysate (1) was preincubated with buffer (1 and 2), $80 \mu \mathrm{M}$ GST-Emi1-CTZBR (3), or $80 \mu \mathrm{M}$ GST-Emil$\mathrm{CT} \triangle \mathrm{ZBR}$ (4). APC immunopurified from mitotic egg extracts was incubated with the Cdc20/protein mixtures. The ability of treated APC to ubiquitylate ${ }^{35}$ S-labeled $\mathrm{N}$ terminus cyclin B fragment was assayed. The percentage of cyclin B unconjugated to ubiquitin by $60 \mathrm{~min}$ was quantitated on a PhosphorImager (graph). (B) $\mathrm{Zn}^{2+}$ chelation strongly reduces the ability of Emil to inhibit the APC in vitro, and addition of $\mathrm{ZnCl}_{2}$ rescues activity. MBP-Emil was incubated with TPEN and then dialyzed into $\mathrm{XB}^{-}$or $\mathrm{XB}^{-}$plus $50 \mu \mathrm{M} \mathrm{ZnCl}_{2}$. IVT Cdc20 (panels 2-5) or rabbit reticulocyte lysate (1) was incubated with buffer (1 and 2), untreated MBP-Emil (3), TPEN-treated MBP-Emil (4), or TPEN-treated MBP-Emil plus $\mathrm{ZnCl}_{2}$ (5). APC was immunopurified and cyclin $\mathrm{B}$ ubiquitylation was analyzed as in $A$.

trolled by its abundance in both the embryo (Reimann et al. 2001) and somatic cells, where Emil accumulates in late $\mathrm{G}_{1}$ much like cyclin A (J. Hsu, J. Reimann, C. Sorensen, J. Lukas, and P. Jackson, in prep.). Previous studies suggested that in addition to the ability of cyclin A/Cdk2 to phosphorylate Cdh1 and inactivate the APCCdh1 in S phase (Lukas et al. 1999; Sørensen et al. 2001), an additional E2F target might block $\mathrm{APC}^{\mathrm{Cdh} 1}$ activity. Like cyclin A, Emil proves to be an E2F target and Emil inhibits Cdh1's ability to block cyclin A accumulation and $\mathrm{S}$ phase entry in vivo (J. Hsu, J. Reimann, C. Sorensen, J. Lukas, and P. Jackson, in prep.). The Drosophila Emil homolog Rcal also blocks Cdh1 activity in flies (F. Sprenger, pers. comm.). As shown here, Emil binds Cdh1 to inhibit $\mathrm{APC}^{\mathrm{Cdh} 1}$ activity in vitro. These data strongly suggest that Emil inactivates the APC ${ }^{\mathrm{Cdh} 1}$ complex to promote cyclin A accumulation at the $G_{1}-S$ transition. Although it is unclear whether Emil continues to inhibit Cdh1 during $S$ phase, as cells approach $G_{2}$
Emil is available to inhibit Cdc20 as it is expressed, thereby promoting cyclin $\mathrm{B}$ accumulation and mitotic entry (Reimann et al. 2001).

APC regulation by the Mad2 proteins is complex, involving additional factors. Mad2/Mad2B inhibit in vitro APC activation by Cdc20/Cdh1, but neither can inhibit preactivated APC complexes in vitro, despite being able to form ternary complexes with activator and APC (Fang et al. 1998a; Kallio et al. 1998; Chen and Fang 2001; Pfleger et al. 2001b; Sudakin et al. 2001; Tang et al. 2001). However, both Mad2 proteins can inhibit activated APC in Xenopus egg extracts and in vivo, suggesting that cellular factors activate Mad2 proteins to inhibit APC activity. Notably, APC inhibition by the SC requires Mad1 and BubR1 in vivo (Hwang et al. 1998; Jin et al. 1998; Chen et al. 1999; Sudakin et al. 2001; Tang et al. 2001). Although Mad2 and BubR1 are present and biochemically competent to inhibit the APC throughout the cell cycle, the APC is only sensitive when phosphorylated in mitosis and when spindle tension and/or microtubule attachment at kinetochores is lost (Abrieu et al. 2001; Skoufias et al. 2001; Sudakin et al. 2001).

In contrast, Emil can bind and inhibit activation of APC prebound to Cdc20 or Cdh1 in vitro and in vivo. The ability of Emil to inhibit an already activated APC would be a necessary feature for Emil to inactivate Cdh1 already bound to the APC at the $G_{1}-S$ transition. Thus, Emil's APC inhibitory activity is likely controlled by Emil protein levels and its ability to bind Cdc20/Cdh1, and not at the level of APC phosphorylation.

APC-dependent cyclin A ubiquitylation is not inhibited by the SC or by Mad2, but is inhibited by Emil (den Elzen and Pines 2001; Geley et al. 2001; our present results). Consistently, Emil itself is destroyed in mitosis slightly before cyclin A levels drop, and Emil is not stabilized by SC activation (J. Hsu, J. Reimann, C. Sorensen, J. Lukas, and P. Jackson, in prep.). Moreover, Emil is not present in the purified Mad2 and BubR1-containing APC inhibitory complex (J. Hsu, V. Sudakin, T. Yen, P. Jackson, unpubl.). Thus, Emil activity is distinct from and independent of Mad2/BubR1.

Both the $\mathrm{N}$ and $\mathrm{C}$ termini of Emil bind the Cdc20 SBR. Mad2 binds just C-terminal to the SBR, and neither Mad2 nor Mad2B prevent Cdc20/Cdh1 substrate binding. Instead, they appear to inhibit substrate release from Cdc20/Cdh1 (Pfleger et al. 2001b), suggesting that Mad2 proteins prevent APC substrate turnover. Emil binding to the SBR directly inhibits substrate binding to Cdc20 in vitro. Thus, Emil appears to prevent substrate ubiquitylation by inhibiting substrate binding, although additional mechanisms may function in vivo.

Both the ZBR (Reimann et al. 2001) and, as we show here, zinc itself are required for the APC inhibitory activity of Emil. Whether zinc fulfills a structural role, facilitates binding interactions, or has another role, such as a catalytic function, is unclear. We did find that zinc chelation did not appear to affect Emil-Cdc20 binding in vitro (J.D.R. Reimann, B. Gardner, and P.K. Jackson, unpubl.).

The identification of other Cdc20/Cdh1-like proteins in various species (e.g., Cooper et al. 2000; Chu et al. 
2001; Wan et al. 2001) suggests additional pathways of APC regulation. An attractive model is that Cdc20, Cdh1, and their homologs regulate the timing of APC activity by regulated binding of specific substrates. The ability of these APC adapters to bind and activate substrate ubiquitylation by the APC might in turn be restricted by a range of inhibitory proteins like Emil and the Mad2 proteins.

\section{Materials and methods}

\section{Recombinant protein and construct preparation}

Full-length, Emil-NT, and Emi1-CT $\Delta$ ZBR constructs were described (Reimann et al. 2001). Emi1-CTZBR (amino acids 323364) was cloned into pGEX6P1. Cdc20-SBR (amino acids 1-118) and Cdc20-MBR (amino acids 119-158) were cloned into pGEX6P1 and pCS2 $2^{+}$vectors. The Emil KE71AA site-directed mutant was cloned into $\mathrm{pCS} 2^{+}-5 \mathrm{mt}$ and verified by sequencing.

All Emil and Cdc20 variants produced as MBP or GST fusion proteins were purified by standard protocols. Cdh1 baculovirus protein was as described (Kramer et al. 2000).

\section{Binding assays}

In vitro GST-Emi1 and GST-Cdc20 binding assays First, 750 nM GST fusion protein was incubated with in vitro translated (IVT) ${ }^{35}$ S-labeled proteins (TNT Promega) in RIPB (100 mM $\mathrm{NaCl}, 50 \mathrm{mM} \beta$-glycerophosphate, $5 \mathrm{mM}$ EDTA, $0.1 \%$ Triton $\mathrm{X}-100,1 \mathrm{mM}$ DTT) $\left(1 \mathrm{~h}\right.$ at $\left.4^{\circ} \mathrm{C}\right)$. Samples were spun $(14,000 \mathrm{rpm}$ for $10 \mathrm{~min})$, supernatant incubated with glutathione agarose (40 min at $4^{\circ} \mathrm{C}$ ), beads washed $4 \times$ in RIPB, and bound proteins analyzed by SDS-PAGE and autoradiography.

Baculovirus reconstitution was performed as described (Reimann et al. 2001).

APC binding assays APC was immunopurified from mitotic or interphase egg extracts on $\alpha \mathrm{Cdc} 27$ beads as described (Fang et al. 1998a) and incubated (room temperature for $1 \mathrm{~h}$ ) with $10 \mu \mathrm{L}$ IVT Cdc20, Cdh1 or rabbit reticulocyte lysate. Beads were washed $2 \times$ in $\mathrm{XB}^{-}(20 \mathrm{mM}$ HEPES, $100 \mathrm{mM} \mathrm{KCl})$, incubated with $4 \mu \mathrm{L}^{35} \mathrm{~S}$-labeled IVT Emil diluted 1:38 in RIPB ( $4^{\circ} \mathrm{C}$ for $\left.45 \mathrm{~min}\right)$, and washed $5 \times$ in Q-A buffer $(20 \mathrm{mM}$ HEPES, $500 \mathrm{mM} \mathrm{KCl}$, $0.5 \%$ NP-40). Bound Emil was analyzed by SDS-PAGE and autoradiography. $\alpha \mathrm{Cdc} 27$ beads were subjected to identical binding and washing conditions. For testing the ability of Emil to inhibit Cdc20 APC binding, $2 \mu \mathrm{L}$ of ${ }^{35}$ S-labeled IVT Cdc20 was prebound to MBP-Emil or MBP before binding to APC beads.

Substrate binding competition assay GST-Cdc20-SBR (1 $\mu \mathrm{M})$ prebound to glutathione agarose was incubated $\left(4^{\circ} \mathrm{C}\right.$ for $\left.45 \mathrm{~min}\right)$ with 1 or $5 \mu \mathrm{M}$ MBP-Emil, his-Emil, Emil with MBP removed, MBP, or BSA in NETN buffer $(20 \mathrm{mM}$ Tris- $\mathrm{HCl}$ at $\mathrm{pH} 7.5,150$ $\mathrm{mM} \mathrm{NaCl}, 0.5 \%$ NP-40, 1 mM DTT, 1 mM EDTA, 1\% aprotinin). Four microliters of ${ }^{35} \mathrm{~S}$-labeled IVT securin was diluted 1:25 in NETN, then incubated with the above mixture $\left(4^{\circ} \mathrm{C}\right.$ for $45 \mathrm{~min}$ ). Beads were washed $5 \times$ in NETN, and bound securin was analyzed by SDS-PAGE and autoradiography.

\section{Zinc chelation experiments}

MBP-Emil protein was incubated $\left(4^{\circ} \mathrm{C}, 24 \mathrm{~h}\right)$ with two changes of $\mathrm{XB}^{-}$plus $2 \mathrm{mM}$ TPEN, then incubated $\left(4^{\circ} \mathrm{C}\right.$ for $\left.3 \mathrm{~h}\right)$ in either $50 \mu \mathrm{M} \mathrm{ZnCl}_{2}$ or $\mathrm{XB}^{-}$, and dialyzed into $\mathrm{XB}^{-}\left(4^{\circ} \mathrm{C}\right.$ for $\left.18 \mathrm{~h}\right)$.

\section{Degradation and ubiquitylation assays}

Emi1 stability experiments in egg extracts ${ }^{35}$ S-labeled IVT Emi1, KE71AA, or $\mathrm{N}$ terminus sea urchin cyclin B substrate (Glotzer et al. 1991) was incubated at $23^{\circ} \mathrm{C}$ in $\Delta 90$ mitotic extracts (Reimann et al. 2001), interphase extracts with IVT Cdh1 (1:20 volume), or interphase extracts with unprogrammed reticulocyte lysate. Aliquots were removed and analyzed by SDSPAGE and autoradiography.

Effect of Emi1 and Mad2 on cyclin A and B stability Buffer, 1 $\mu \mathrm{M}$ MBP-Emi1, or $20 \mu \mathrm{M}$ GST-Mad2 fusion protein was added to cycling extracts (Murray 1991). Aliquots were removed at the indicated times, and endogenous cyclin A and B levels were assayed by immunoblotting with $\alpha$ cyclin B2 or acyclin A1 antibodies.

Effect of Emi1 on APC Cdh1 activity in extracts ${ }^{35}$ S-labeled IVT $\mathrm{Xl}$ cyclin B1 (amino acids 2-97) fragment or securin was added (1:20 volume) to interphase extracts preincubated with either $\mathrm{XB}^{-}$buffer, IVT Cdh1 (1:25 volume) plus $\mathrm{XB}^{-}$buffer, or IVT Cdh1 (1:25 volume) plus $1 \mu \mathrm{M}$ MBP-Emil. Aliquots were removed and analyzed by SDS-PAGE and autoradiography.

APC2/APC11 substrate-independent ubiquitylation reaction Twenty $\mu \mathrm{M}$ MBP, $20 \mu \mathrm{M}$ MBP-Emil, or $60 \mu \mathrm{M}$ GST-Mad2 was incubated at room temperature in ULAA buffer (50 mM Tris at $\mathrm{pH} 7.5,5 \mathrm{mM} \mathrm{MgCl} 2,2 \mathrm{mM} \mathrm{NaF}, 0.6 \mathrm{mM} \mathrm{DTT}$ ) containing $1.5 \mathrm{ng} / \mathrm{\mu L}$ baculovirus expressed and purified APC2/

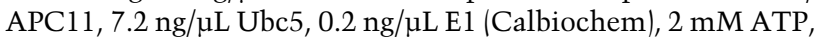
$10 \mathrm{nM}$ okadaic acid, and $3.2 \mathrm{ng} / \mu \mathrm{L}$ Flag-ubiquitin. Aliquots were removed at the indicated times and analyzed for polyubiquitin chains by immunoblotting with $\alpha$ Flag antibody (Sigma).

In vitro APC assays Mitotic or interphase extract aCdc27 immunoprecipitates were incubated $\left(25^{\circ} \mathrm{C}\right.$ for $\left.1 \mathrm{~h}\right)$ with $10 \mu \mathrm{L}$ IVT $\mathrm{Cdc} 20$ or Cdh 1 preincubated $\left(4^{\circ} \mathrm{C}\right.$ for $\left.30 \mathrm{~min}\right)$ with protein or buffer as indicated in the figure legend, washed in $\mathrm{XB}^{-}$, and assayed for cyclin ubiquitylation as described (Fang et al. $1998 b)$.

\section{Acknowledgments}

We thank C. Pfleger and M. Kirschner for securin cDNA and unpublished results, E. Kramer and J. Peters for Cdh1 constructs and antibodies, T. Hunt for $X 1$ cyclin A and B antibodies, M. Dobles and P. Sorger for GST-Mad2 cDNA, Jianing Huang and Ruby Daniel (Rigel Pharmaceuticals) for Flag-Ubiquitin, and R. Deshaies, G. Fang, A. Eldridge, J. Hsu, and D. Hansen for comments on the manuscript. This work was supported by the NIGMS Medical Scientists Training Grant GM07365 (J.R.), INSERM (F.M.), and NIH grants GM54811 and GM60439 (P.J).

The publication costs of this article were defrayed in part by payment of page charges. This article must therefore be hereby marked "advertisement" in accordance with 18 USC section 1734 solely to indicate this fact.

\section{References}

Abrieu, A., Magnaghi-Jaulin, L., Kahana, J.A., Peter, M., Castro, A., Vigneron, S., Lorca, T., Cleveland, D.W., and Labbé, J.C. 
2001. Mps1 is a kinetochore-associated kinase essential for the vertebrate mitotic checkpoint. Cell 106: 83-93.

Burton, J.L. and Solomon, M.J. 2001. D box and KEN box motifs in budding yeast Hsllp are required for APC-mediated degradation and direct binding to Cdc20p and Cdh1p. Genes \& Dev. 15: 2381-2395.

Chen, J. and Fang, G. 2001. MAD2B is an inhibitor of the anaphase-promoting complex. Genes \& Dev. 15: 1765-1770.

Chen, R.H., Brady, D.M., Smith, D., Murray, A.W., and Hardwick, K.G. 1999. The spindle checkpoint of budding yeast depends on a tight complex between the Mad1 and Mad2 proteins. Mol. Biol. Cell 10: 2607-2618.

Chu, T., Henrion, G., Haegeli, V., and Strickland, S. 2001. Cortex, a Drosophila gene required to complete oocyte meiosis, is a member of the Cdc20/fizzy protein family. Genesis 29: $141-152$.

Cohen-Fix, O., Peters, J.M., Kirschner, M.W., and Koshland, D. 1996. Anaphase initiation in Saccharomyces cerevisiae is controlled by the APC-dependent degradation of the anaphase inhibitor Pds1p. Genes \& Dev. 10: 3081-3093.

Cooper, K.F., Mallory, M.J., Egeland, D.B., Jarnik, M., and Strich, R. 2000. Amalp is a meiosis-specific regulator of the anaphase promoting complex/cyclosome in yeast. Proc. Natl. Acad. Sci. 97: 14548-14553.

den Elzen, N. and Pines, J. 2001. Cyclin A is destroyed in prometaphase and can delay chromosome alignment and anaphase. J. Cell Biol. 153: 121-136.

Dong, X., Zavitz, K.H., Thomas, B.J., Lin, M., Campbell, S., and Zipursky, S.L. 1997. Control of $\mathrm{G}_{1}$ in the developing Drosophila eye: rcal regulates Cyclin A. Genes \& Dev. 11: 94 105.

Fang, G., Yu, H., and Kirschner, M.W. 1998a. The checkpoint protein MAD2 and the mitotic regulator CDC20 form a ternary complex with the anaphase-promoting complex to control anaphase initiation. Genes \& Dev. 12: 1871-1883.

Fang, G., Yu, H., and Kirschner, M.W. 1998b. Direct binding of CDC20 protein family members activates the anaphase-promoting complex in mitosis and G1. Mol. Cell 2: 163-171.

Geley, S., Kramer, E., Gieffers, C., Gannon, J., Peters, J., and Hunt, T. 2001. Anaphase-promoting complex/cyclosome-dependent proteolysis of human cyclin A starts at the beginning of mitosis and is not subject to the spindle assembly checkpoint. J. Cell Biol. 153: 137-148.

Glotzer, M., Murray, A.W., and Kirschner, M.W. 1991. Cyclin is degraded by the ubiquitin pathway. Nature 349: 132-138.

Gmachl, M., Gieffers, C., Podtelejnikov, A.V., Mann, M., and Peters, J.M. 2000. The RING-H2 finger protein APC11 and the E2 enzyme UBC4 are sufficient to ubiquitinate substrates of the anaphase-promoting complex. Proc. Nat1. Acad. Sci. 97: 8973-8978.

Hilioti, Z., Chung, Y.S., Mochizuki, Y., Hardy, C.F., and CohenFix, O. 2001. The anaphase inhibitor Pds1 binds to the APC/ $\mathrm{C}$-associated protein $\mathrm{Cdc} 20$ in a destruction box-dependent manner. Curr. Biol. 11: 1347-1352.

Hunt, T., Luca, F.C., and Ruderman, J.V. 1992. The requirements for protein synthesis and degradation, and the control of destruction of cyclins A and B in the meiotic and mitotic cell cycles of the clam embryo. J. Cell Biol. 116: 707-724.

Hwang, L.H., Lau, L.F., Smith, D.L., Mistrot, C.A., Hardwick, K.G., Hwang, E.S., Amon, A., and Murray, A.W. 1998. Budding yeast Cdc20: A target of the spindle checkpoint. Science 279: 1041-1044.

Jin, D.Y., Spencer, F., and Jeang, K.T. 1998. Human T cell leukemia virus type 1 oncoprotein Tax targets the human mitotic checkpoint protein MAD1. Cell 93: 81-91.

Kallio, M., Weinstein, J., Daum, J.R., Burke, D.J., and Gorbsky,
G.J. 1998. Mammalian p55CDC mediates association of the spindle checkpoint protein Mad2 with the cyclosome/anaphase-promoting complex, and is involved in regulating anaphase onset and late mitotic events. J. Cell Biol. 141: 13931406.

Kim, S.H., Lin, D.P., Matsumoto, S., Kitazono, A., and Matsumoto, T. 1998. Fission yeast Slp1: An effector of the Mad2dependent spindle checkpoint. Science 279: 1045-1047.

Kramer, E.R., Gieffers, C., Hölzl, G., Hengstschläger, M., and Peters, J.M. 1998. Activation of the human anaphase-promoting complex by proteins of the CDC20/Fizzy family. Curr. Biol. 8: 1207-1210.

Kramer, E.R., Scheuringer, N., Podtelejnikov, A.V., Mann, M., and Peters, J.M. 2000. Mitotic regulation of the APC activator proteins CDC20 and CDH1. Mol. Biol. Cell 11: 1555-1569.

Lorca, T., Castro, A., Martinez, A.M., Vigneron, S., Morin, N., Sigrist, S., Lehner, C., Dorée, M., and Labbé, J.C. 1998. Fizzy is required for activation of the APC/cyclosome in Xenopus egg extracts. EMBO J. 17: 3565-3575.

Lukas, C., Sørensen, C.S., Kramer, E., Santoni-Rugiu, E., Lindeneg, C., Peters, J.M., Bartek, J., and Lukas, J. 1999. Accumulation of cyclin B1 requires E2F and cyclin-A-dependent rearrangement of the anaphase-promoting complex. Nature 401: 815-818.

Luo, X., Fang, G., Coldiron, M., Lin, Y., Yu, H., Kirschner, M.W., and Wagner, G. 2000. Structure of the Mad2 spindle assembly checkpoint protein and its interaction with Cdc20. Nat. Struct. Biol. 7: 224-229.

Murray, A.W. 1991. Cell cycle extracts. Methods Cell Biol. 36: 581-605.

Page, A.M. and Hieter, P. 1999. The anaphase-promoting complex: New subunits and regulators. Annu. Rev. Biochem. 68: 583-609.

Pfleger, C.M. and Kirschner, M.W. 2000. The KEN box: An APC recognition signal distinct from the $\mathrm{D}$ box targeted by Cdh1. Genes \& Dev. 14: 655-665.

Pfleger, C.M., Lee, E., and Kirschner, M.W. 2001a. Substrate recognition by the Cdc20 and Cdh 1 components of the anaphase-promoting complex. Genes \& Dev. 15 2396-2407.

Pfleger, C.M., Salic, A., Lee, E., and Kirschner, M.W. 2001b. Inhibition of Cdh1-APC by the MAD2-related protein MAD2L2: A novel mechanism for regulating Cdh1. Genes \& Dev. 15: 1759-1764.

Prinz, S., Hwang, E.S., Visintin, R., and Amon, A. 1998. The regulation of Cdc20 proteolysis reveals a role for APC components $\mathrm{Cdc} 23$ and $\mathrm{Cdc} 27$ during $\mathrm{S}$ phase and early mitosis. Curr. Biol. 8: 750-760.

Reimann, J.D., Freed, E., Hsu, J.Y., Kramer, E.R., Peters, J.M., and Jackson, P.K. 2001. Emil is a mitotic regulator that interacts with Cdc20 and inhibits the anaphase promoting complex. Cell 105: 645-655.

Shah, J.V. and Cleveland, D.W. 2000. Waiting for anaphase: Mad2 and the spindle assembly checkpoint. Cell 103: 9971000.

Shirayama, M., Zachariae, W., Ciosk, R., and Nasmyth, K. 1998. The Polo-like kinase Cdc5p and the WD-repeat protein $\mathrm{Cdc} 20 \mathrm{p} /$ fizzy are regulators and substrates of the anaphase promoting complex in Saccharomyces cerevisiae. EMBO J. 17: 1336-1349.

Sigrist, S.J. and Lehner, C.F. 1997. Drosophila fizzy-related down-regulates mitotic cyclins and is required for cell proliferation arrest and entry into endocycles. Cell 90: 671-681.

Skoufias, D.A., Andreassen, P.R., Lacroix, F.B., Wilson, L., and Margolis, R.L. 2001. Mammalian mad2 and bub1/bubR1 recognize distinct spindle-attachment and kinetochore-tension checkpoints. Proc. Nat1. Acad. Sci. 98: 4492-4497. 
Sørensen, C.S., Lukas, C., Kramer, E.R., Peters, J.M., Bartek, J., and Lukas, J. 2001. A conserved cyclin-binding domain determines functional interplay between anaphase-promoting complex-Cdh1 and cyclin A-Cdk2 during cell cycle progression. Mol. Cell. Biol. 21: 3692-3703.

Sudakin, V., Chan, G.K., and Yen, T.J. 2001. Checkpoint inhibition of the APC/C in HeLa cells is mediated by a complex of BUBR1, BUB3, CDC20, and MAD2. J. Cell Biol. 154: 925936.

Tang, Z., Bharadwaj, R., Li, B., and Yu, H. 2001. Mad2-independent inhibition of APC-Cde20 by the mitotic checkpoint protein BubR1. Dev. Cell 1: 227-237.

Visintin, R., Prinz, S., and Amon, A. 1997. CDC20 and CDH1: A family of substrate-specific activators of APC-dependent proteolysis. Science 278: 460-463.

Wan, Y. and Kirschner, M.W. 2001. Identification of multiple $\mathrm{CDH} 1$ homologues in vertebrates conferring different substrate specificities. Proc. Natl. Acad. Sci. 98: 13066-13071.

Zachariae, W. and Nasmyth, K. 1999. Whose end is destruction: Cell division and the anaphase-promoting complex. Genes \& Dev. 13: 2039-2058.

Zachariae, W., Schwab, M., Nasmyth, K., and Seufert, W. 1998. Control of cyclin ubiquitination by CDK-regulated binding of Hctl to the anaphase promoting complex. Science 282: $1721-1724$.

Zhang, Y. and Lees, E. 2001. Identification of an overlapping binding domain on Cdc20 for Mad2 and anaphase-promoting complex: Model for spindle checkpoint regulation. Mol. Cell. Biol. 21: 5190-5199. 


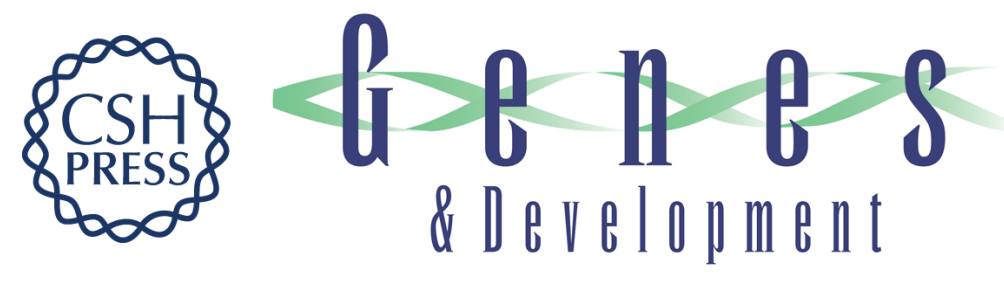

\section{Emi1 regulates the anaphase-promoting complex by a different mechanism than Mad2 proteins}

Julie D.R. Reimann, Bryan E. Gardner, Florence Margottin-Goguet, et al.

Genes Dev. 2001, 15:

Access the most recent version at doi:10.1101/gad.945701

References This article cites 44 articles, 28 of which can be accessed free at: http://genesdev.cshlp.org/content/15/24/3278.full.html\#ref-list-1

License

Email Alerting

Receive free email alerts when new articles cite this article - sign up in the box at the top Service right corner of the article or click here.

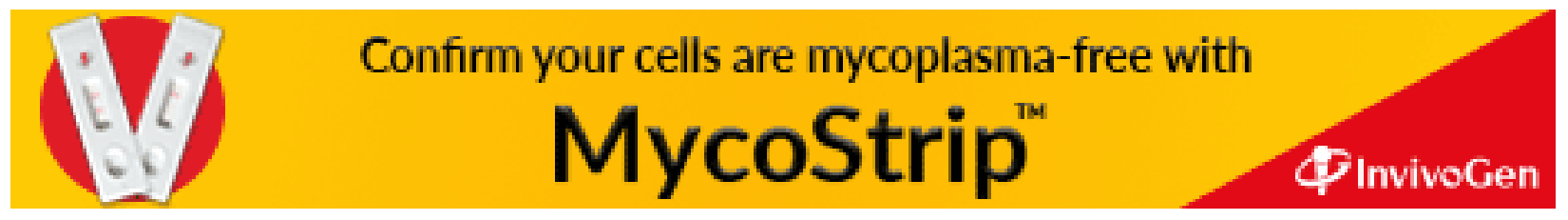

